\title{
HILDA HILST E GEORGES BATAILLE DE MÃOS DADAS COM A MORTE
}

\section{HILDA HILST AND GEORGES BATAILLE HOLDING HANDS WITH DEATH}

\section{Aline Leal Fernandes Barbosa ${ }^{1}$}

RESUMO: O erotismo, o sagrado e a morte são temas recorrentes nas obras de Hilda Hilst e de Georges Bataille. Apostando no movimento contínuo de transgressão dos limites do humano, a morte, seu caráter irrevogável, será a experiência radical de continuidade a que o erotismo e o sagrado tendem, exibindo a passagem entre a animalidade e a humanidade. E uma vez que a morte é sempre a de um terceiro, pretendemos, neste artigo, a partir da obra e da trajetória de Hilda Hilst e de Georges Bataille, esboçar algumas paisagens poéticas do espetáculo do ver-se morrer através do outro.

PALAVRAS-CHAVE: Morte. Erotismo. Sagrado. Hilda Hilst. Georges Bataille.

\begin{abstract}
The erotic, the sacred and death are recurrent themes in the works of Hilda Hilst and Georges Bataille. Betting on the continuous movement that transgresses the limits of what it means to be human, death, in its irrevocable character, will be the radical experience of continuity to which the erotic and the sacred tend, exemplifying the passage between animality and humanity. And since death is always that tertium quid, we intend in this article, based on the work and trajectory of Hilda Hilst and Georges Bataille, to outline some poetic landscapes about the spectacle of seeing oneself die through the other.
\end{abstract}

KEYWORDS: Death. The Erotic. The Sacred. Hilda Hilst. Georges Bataille

\footnotetext{
${ }^{1}$ Doutora (2017) e Mestre (2013) em Literatura, cultura e contemporaneidade pela Pontifícia Universidade Católica do Rio de Janeiro. Graduada em Jornalismo (2006) pela mesma universidade. Rio de Janeiro, Brasil. E-mail: alinelfbarbosa@gmail.com
} 
Para quem respirou a Morte, que desolação o odor do Verbo! Emil Cioran, Silogismos da amargura.

Este sol que clareia, este sol que cega. Dar à luz, ceder às trevas, nascer morrer etc. Quero do sol a sua potência completa, violação, fusão de corpos, abismo de morte. Fascínio da morte, angústia da morte: o ponto em que o coração desfalece $^{2}$. A morte o ápice da vida, do humano e do não humano, profunda afirmação, profunda subversão.

Morte: sol negro ${ }^{3}$, noite definitiva. Assim como a vida tende à morte, em que ela se afirmará, os movimentos de que queremos tratar, e que permeiam as obras de Hilda Hilst e de Georges Bataille, também miram seu clímax: o erotismo, o sagrado, a poesia - sol fatal sobre nossas cabeças; intensidade de calor que derrete os limites, risco assumido de fusão.

Do sol negro temos a seguinte acepção, encontrada no Dicionário dos Símbolos: "De acordo com as tradições, o sol negro é uma pré-representação do desencadeamento das forças destrutivas no universo, numa sociedade ou num indivíduo. É o prenúncio da catástrofe, do sofrimento e da morte, a imagem invertida do sol em seu zênite." (CHEVALIER, GHEERBRANT, 1998, p. 840).

\footnotetext{
2 "Toda a operação do erotismo tem por fim atingir o ser no mais íntimo, no ponto em que o coração desfalece" (BATAILLE, 2014, p. 41).

${ }^{3}$ Aqui referido à morte, o "sol negro" é mais comumente metáfora da melancolia. O livro Sol negro - depressão e melancolia (1989), de Julia Kristeva, consolidou esta expressão.
} 
Daí que a morte - a catástrofe, o sofrimento - será fonte de angústia na medida em que é também fonte de desejo, em que o ser se satisfaz naquilo que lhe dá medo, por isso espelho - imagem invertida - da vida em sua potência mais vigorosa, daí situar-se a um passo ínfimo da tragédia, no que ela tem de representação (espetáculo) e horror.

Eixo central da vida, além disso sua culminação, a morte estabelecerá a dimensão contínua a que tais movimentos (o erotismo, o sagrado, a poesia) tendem, e também a sua promessa: "a morte, ruptura dessa descontinuidade individual a que a angústia nos prende, se propõe a nós como uma verdade mais eminente do que a vida" (BATAILLE, 2014, p. 42). Desse modo, se queremos da vida a verdade, convém buscá-la nos extremos, onde a vida convulsiona e (se) gasta, ali onde ela quiçá não mais poderá ser chamada de vida, pois destituída de suas formas, contratos e duração.

Faces opostas e complementares, apartadas e indissociáveis, morte e vida em movimento paródico. Parodiando a linguagem de $O$ ânus solar (BATTAILE, 2007), que diz estar claro ser o mundo paródia pura, podemos dizer, por nossa conta e risco, que a morte é paródia da vida, a vida é paródia da morte, assim como a angústia e a dor são paródias da felicidade e o frenesi amoroso paródia do desespero arrasador. E assim que o vagido é paródia do último suspiro, e o túmulo paródia do início e do fim. Enfim, queremos dizer da cópula que liga uma coisa à outra, de modo que "tudo estaria ligado se um único olhar descobrisse a totalidade do percurso deixado por um fio de Ariana que conduz o pensamento no seu próprio labirinto" (BATAILLE, 2007, p. 45). Olhar total, mirada da morte. Também a figura hegeliana do sábio - do saber absoluto - evoca o movimento circular de totalidade, e "consistiria no fechamento do círculo do conhecimento, em que saber e não saber, razão e loucura, potência e impotência, soberania e servidão, coincidiriam" (PENNA; BATAILLE, 2013, s/p), como aponta João Camillo Penna ${ }^{4}$ na apresentação à tradução do ensaio de Bataille "Hegel, la mort et le sacrifice", Hegeliennes",

\footnotetext{
${ }^{4}$ Bataille aprofunda seu contato com a obra de Hegel através do curso sobre a Fenomenologia do Espírito que Alexandre Kojève ministrou entre 1933 e 1939 na Escola Prática de Altos Estudos (EPHE). A princípio dizendo-se anti-hegeliano, posteriormente Bataille vai se propor a realizar um Hegel "misturado com tintas nietzschianas", como João Camillo Penna descreve na apresentação da tradução de Hegel, la mort et le sacrifice. Penna diz: "Para Bataille, trata-se antes de mais nada de 'experimentar' Hegel, de transformar o programa hegeliano em experiência: 'por contágio, imitação, realizo em mim o movimento circular. Realizar em si o círculo do saber consistiria em suma, nada mais nada menos, do que realizar no ipse, ou seja, em si, a totalidade universal, tornando-se... Deus"'. (Penna; Bataille, 2013, s/p).

5 BATTAILlE, Georges. Hegel, a morte e o sacrifício. Traduzido por João Camilo Penna. Revista ALEA. Rio de Janeiro, v. 15/2, p. 389-413, jul-dez 2013. Disponível em: $<$ http://www.scielo.br/scielo.php?script $=$ sci arttext\&pid=S1517-106X2013000200009 $>$. Acesso em: 13 jun. 2017.
}

${ }^{6}$ A revista Deucalion: Cahiers de philosophie (1946-1957), com seis edições, teve como fundadores Jean Wahl e Pierre Thévenaz, e fazia parte da coleção "Être et Penser", das Éditions 
Daí que os movimentos de morte, em sua violência, propiciem a violação dos corpos e a dissolução (relativa) do sujeito, uma despossessão "semelhante ao vaivém das ondas que se penetram e se perdem umas nas outras" (BATAILLE, 2014, p. 41). O homem está separado do homem e isolado na natureza, a qual ele nega em privilégio da linguagem e do discurso, isto é, em privilégio do próprio homem, de sua humanidade, enquanto as ondas, e a mosca, para usar o exemplo que Bataille utilizou no ensaio que citamos, estão perdidas na natureza, "na totalidade do que é", e, uma vez indistintas, não desaparecem ${ }^{7}$.

Para se separar dos outros, a "mosca" precisaria da força monstruosa do entendimento: então ela se nomearia, fazendo o que em geral a linguagem opera pelo entendimento, que só ele funda a separação dos elementos, e ao fundá-la se funda sobre ela, no interior de um mundo formado de entidades separadas e nomeadas. Mas nesse jogo o animal humano encontra a morte: ele encontra precisamente a morte humana, a única que amedronta, que horripila, mas amedronta e horripila apenas o homem absorvido na consciência do seu desaparecimento futuro, enquanto ser separado e insubstituível; a única verdadeira morte, que supõe a separação e, pelo discurso que separa, a consciência de ser separado. (BATAILLE, 2013, s/p)

Para negar a natureza, foi necessário lançar mão da violência do entendimento, uma verdadeira "luta histórica em que o Homem se constituiu como 'Sujeito', ou como 'Eu abstrato' do 'Entendimento', como ser separado e nomeado" (BATAILLE, 2013, s/p). O nome será, portanto, essa quebra da natureza total, ação separadora do entendimento, fragmentação do mundo. E esse homem que se separa do animal, tornando-se um "eu-pessoal puro" (Ibid, s/p), determinado pelo nome, é temporal e finito, e logo está condenado a desaparecer definitivamente. De modo que a morte - fruto da violência da negatividade do homem contra a natureza - assegura a existência do homem, sua liberdade, historicidade, individualidade.

Também o erotismo distingue o ser humano da animalidade na medida de uma busca psicológica na atividade sexual independente da finalidade de reprodução, incitada pelos interditos que contornam essa atividade. Mas igualmente aí trata-se de perder-se, desafiar os próprios interditos que o constituem, de modo que "o ser se perde objetivamente, mas então o sujeito se identifica com o objeto que se perde" (BATAILLE, 2014, p. 55). Ficamos então

la Baconnière. A edição número 5, "Études Hegeliennes", contou com as seguintes colaborações, entre outras: Alexandre Kojève, Georges Bataille, Raymond Queneau, Jean Wahl, Eric Weil, Robert Minder, Rachel Bespaloff.

${ }^{7}$ Neste ensaio, Bataille observa: "Sem dúvida, a mosca individual morre, mas estas moscas aqui são as mesmas do ano passado. As do ano passado estariam mortas?... É possível, mas nada desapareceu. As moscas permanecem, iguais a elas mesmas, como o são as ondas do mar. Aparentemente é forçoso ser assim: um biólogo separa esta mosca aqui do turbilhão, um traço de pincel basta. Mas ele a separa para si mesmo, ele não a separa para as moscas" (BATAILLE, 2013, s/p). 
com esse processo bastante vertiginoso e mesmo circular em que o erotismo se desenvolve na medida em que o homem se afasta da atividade sexual rudimentar e animal, e logo essa sexualidade envergonhada confrontará os interditos que a constituíram no limite entre o homem e o animal e na nostalgia da continuidade perdida. Em $O$ culpado, Bataille confessa: "o que realmente amamos, amamos sobretudo na vergonha" (BATAILLE, 2017, p. 17), fazendo do constrangimento social uma modalidade do erótico.

Em $O$ erotismo, Bataille observa que, se a consciência da morte será indicativo da transição do homem em meio à natureza ao homem "civilizado", também a sexualidade envergonhada, isto é, as restrições às liberdades sexuais serão determinantes na consolidação das estruturas sociais, que, por sua vez, distanciam progressivamente o homem da natureza. O trabalho será o principal fator da regulamentação da sexualidade e da morte, elevando tabus nos dois domínios mais importantes da vida. Bataille observa: "Podemos dizer somente que, em oposição ao trabalho, a atividade sexual é uma violência que, enquanto impulso imediato, poderia perturbar o trabalho: uma coletividade laboriosa, no momento do trabalho, não pode ficar à sua mercê." (BATAILLE, 1987, p. 33)

Hilda Hilst, em resposta à pergunta de Jorge Coli ao Cadernos de Literatura do Instituto Moreira Salles sobre a relação entre animalidade e humanidade, afirma: "Acho que os animais são puros, não têm consciência. Já o homem, não: é safado". (HILST et al, 1999, p. 34). A safadeza será então indício de consciência, logo de humanidade, uma vez que requer certo grau de elaboração da atividade sexual, que será incitada pelos interditos que definem do desejo à angústia. Assim não parece inoportuno ter sido Lori Lamby a protagonista da estreia de Hilda Hilst em sua declarada fase pornográfica: na medida em que, na criança, a pureza ainda se apresenta - ou deve se apresentar -, a ignorância dos tabus sistematicamente rompidos acentua tanto o descolamento da criança do que deve constituí-la, isto é, os próprios interditos que acompanham a formação do ser, como a força violenta de transgressão dos seus exploradores: o papi e a mami proxenetas, o tio Abel. ${ }^{8} \mathrm{O}$ homem é safado, diz Hilda Hilst, isso porque ele sabe o que está fazendo, e a medida da sua consciência é a medida da sua culpa, a medida do seu prazer.

O humano é o ser habilitado para o erotismo tanto quanto para a morte, e o abismo de que é originário é o mesmo abismo de sua desordem, é ali onde ele se encontra e esse é o local de sua perdição. Ora, se por sua vez a mosca está perdida entre as moscas, as ondas na multiplicidade das ondas, no erotismo os corpos estarão entre os corpos, o sujeito entre o objeto, na grande cópula que se anuncia em $O$ ânus solar, apostando no deslizamento das identidades, no processo de

\footnotetext{
${ }^{8}$ A infância será um momento privilegiado para Bataille, por ser uma fase em que "as disposições do indivíduo se mostram soberanas, na recusa de tudo aquilo que, por meio do cálculo e da razão normativa, pretende regular o desejo e o dispêndio", como aponta Contador Borges na orelha de A literatura e o mal (AUTÊNTICA, 2015). E assim, como Borges afirma, a literatura será a "infância reencontrada".
} 
aquisição e perda da humanidade e da animalidade, também na fragmentação e desfragmentação da linguagem.

Mas por que será que Bataille vai falar em paródia, em "a mesma coisa com uma forma decepcionante" (BATAILLE, 2007, p. 45)? Eliane Robert Moraes aponta para recurso semelhante entre os surrealistas, movimento do qual Bataille se aproxima e com o qual acabará rompendo. Paródia como um devir ininterrupto dos objetos, como encontro fortuito ${ }^{9}$, indicando a instabilidade das imagens do mundo exterior: "De Lautréamont aos autores surrealistas, a paródia tornou-se, por excelência, um exercício de desconfiança diante das imagens imediatas que o mundo oferecia" (MORAES, 2002, p. 47). A imagem da "mesa de dissecação", evocada por Lautréamont ${ }^{10}$ numa passagem de Os cantos de Maldoror (1869), será aplicada como fórmula do movimento surrealista, que tinha como base a associação livre de ideias, como apresentado no primeiro Manifesto. A frase de Maldoror "Belo como [...] o encontro fortuito de uma máquina de costura e um guarda-chuva sobre uma mesa de dissecação" 11 (LAUTRÉAMONT apud MORAES, 2002, p. 40) é indicativa do grau de arbitrariedade das composições delirantes apresentadas pelo escritor e estimadas pelos surrealistas.

Assim como à atividade sexual e à morte serão impostos interditos para a fundação do mundo real do trabalho e da duração, à linguagem também será imposto um funcionamento restrito para ser servil. Por sua vez o jogo paródico, na aproximação de realidades distantes, revelando novos e imprevisíveis encontros, ampliará a liberdade frente aos constrangimentos gramaticais e linguísticos colocados pelas relações consagradas, e assim, o "ouro, a água, o equador ou o crime podem ser indiferentemente enunciados como o princípio das coisas" (BATAILLE, 2007, p. 46). Propõe-se, portanto, exibir o avesso das palavras, ali onde elas resistem a se encaixar e a nomear, como acontece em nossa cultura com os movimentos do desejo, da morte, do dispêndio, da poesia.

Bataille vai preservar o tom paródico em sua obra, apostando na cópula erótica entre todas as coisas, inclusive acusando o movimento bretoniano de idealista e querendo ir além dele na incorporação da totalidade: "se o surrealismo, se o homem surrealista quer realmente se entregar à totalidade da existência, logicamente ele não pode excluir o que é baixo, o que é vil." (SCHEIBE;

\footnotetext{
${ }^{9}$ Eliane Robert Moraes cita a famosa frase de Lautréamont proferida por Max Ernst para definir a colagem: "encontro fortuito de duas realidades distantes em um plano não pertinente" (LAUTRÉAMONT apud MORAES, 2001, p. 44). Para os surrealistas, a paródia pôde também ser considerada como extensão dos procedimentos de colagem.

${ }^{10}$ Conde de Lautréamont é o pseudônimo literário de Isidore Lucien Ducasse (1846-1870). Poeta uruguaio que viveu na França, foi considerado por Breton como uma espécie de precurssor dos surrealistas.

${ }^{11}$ Mervyn, um "filho da loira Inglaterra", um dos muitos adolescentes bonitos de Os cantos de Maldoror, é tão belo como "o encontro fortuito de uma máquina de costura e um guarda-chuva sobre uma mesa de dissecação".
} 
BATAILLE, 2014, p. 11) ${ }^{12}$. Assim, Bataille indica o baixo materialismo como fundamento do seu pensamento heterológico, valorizando os dejetos, os restos, o inassimilável na direção de um pensamento do impossível.

Marcelo Jacques de Moraes, no ensaio "Georges Bataille e as formações do abjeto" (MORAES, 2005), faz uma ampla investigação do informe batailliano e discorre a respeito do termo "heterologia", como "a ciência do que é completamente outro [tout autre]" (BATAILLE apud MORAES, 2005, p. 112), que Bataille propõe pela primeira vez no ensaio $O$ valor de uso de D.A.F. Sade (1930). Aí, Bataille acusa o movimento surrealista, representado na figura de seu principal expoente, André Breton, de reduzir a obra de Sade ao seu valor "literário", limitando-se a um "gozo bibliofílico"13, e desse modo domesticando sua potência. Assim, o pensamento heterológico vai privilegiar as "forças excremenciais" em contraponto às "forças de apropriação", o "valor de uso improdutivo" em contraponto ao "valor de troca", oferecendo resistência aos movimentos do consumo, da racionalidade, enfim, da ideia, a fim de que o heterogêneo não seja assimilado pelo homogêneo. Nesse sentido, Marcelo Jacques de Moraes vai observar: "a questão fundamental para Bataille parece ser a de sustentar o que ele chama de 'irrealidade prática' do dejeto, ou seja, manterlhe a dimensão de corpo estranho ao sujeito sem convertê-lo em ideia, em forma acabada, ou seja sem dispô-lo à 'fabricação' e ao 'consumo racional'" (MORAES, 2005, p. 114).

Sabemos do flerte de Bataille com o surrealismo, do seu posterior rompimento e das acusações que ele faz e das que lhe são dirigidas pelo movimento. Os anos de 1929-1930 representarão o auge desta crise: o segundo Manifesto surrealista é publicado no último número da revista La Révolution Surréaliste $^{14}$ (1929), dirigida por Breton, contendo ataques à Bataille e a outros membros dissidentes, e, em janeiro de 1930, é publicado o panfleto Un cadavre ${ }^{15}$,

\footnotetext{
${ }^{12}$ De acordo com Fernando Scheibe, tradutor de Bataille para a editora Autêntica, Bataille acusa o surrealismo bretoniano de idealismo e de utilização hipócrita de Sade, nos textos "Le prefixe 'sur' un surréalisme et surhome" e em "La valeur d'usage de D.A.F. de Sade" (Scheibe; Bataille, 2014, p. 11).

${ }^{13}$ Expressão utilizada por Denis Hollier no ensaio $O$ valor de uso do impossível.
}

HOLLIER, Denis. O valor de uso do impossível Alea, Rio de Janeiro, v. 15, n. 2, 2013, pp. 279302. Disponível em: <http://dx.doi.org/10.1590/S1517-106X2013000200002>. Acesso: 14 jul. 2017.

${ }^{14}$ La Révolution Surrealiste, revista do movimento surrealista em Paris, teve doze edições publicadas entre 1924 e 1929. Seguiu-se a esta publicação Le surrealisme au service de la révolution, lançada esporadicamente entre 1930 e 1933.

${ }^{15}$ No fim de 1924, por ocasião da morte de Anatole France e as homenagens a ele conferidas, André Breton institui um tribunal para julgá-lo, uma vez que os surrealistas o consideravam um defensor da burguesia e de seus costumes moralistas. Além do julgamento, Breton publica um panfleto contra France, chamado Un cadavre, em que participa com o texto "Refus de Inhumer" (Recusa de inumar), mostrando que os surrealistas recusavam-se a participar das homenagens conferidas por sua morte. Retomando o título e o formato do Cadavre contra Anatole France, alguns dissidentes do surrealismo e atacados por Breton no Segundo Manifesto reeditarão o 
em resposta a este ataque, que Bataille, Jacques Prévert, Raymond Queneau, Robert Desnos, entre outros, organizaram contra Breton. As críticas contidas neste panfleto acusavam o "papa do surrealismo" sobretudo de autoritarismo e de hipocrisia, chamando-o, além de "papa", de "tira" e "cura". Michel Surya, em Bataille, la mort à l'œuvre, discorre a respeito da relação entre os dois proeminentes intelectuais franceses do século XX: "O que é surpreendente não é que discordassem, mas a obstinação de ambos de não se ignorarem mutuamente" (SURYA, 2002, p. 228) ${ }^{16}$. Em 1935, Bataille e Breton se reconciliam para a organização do grupo antifascista Contre-attaque - Union de lutte de intellectuels révolutionnaires, que, no entanto, por desacordos internos, teve curta duração (1935-1936).

\section{O NOME DA MORTE}

Entregar-se à totalidade da existência será contemplar a morte, seu alcance global? Daí que a morte apareça como miragem e dispositivo poético, como lugar privilegiado para se pensar as tensões de atividade limítrofe, derrubar os limites ainda que temporariamente, de modo que Georges Bataille e Hilda Hilst mantiveram-na como foco de luz solar, insuportável e incontornável, temida e desejada a morte. Além disso à morte tenderam poeticamente, apostando nessa linguagem, e no que ela tem de transgressão e perda, como motor para a atividade literária.

Se o trabalho transforma a natureza e cria o mundo, fundando o homem em sua duração, a poesia, por sua vez, nos conduz, como a morte, à negação da duração individual, de modo que operam movimentos antagônicos: "O homem trabalha e combate: transforma o dado ou a natureza: cria, ao destruí-la, o mundo, um mundo que não existia. Há, de um lado, poesia: a destruição, surgida e se diluindo, de uma cabeça ensanguentada; de outro, Ação: o trabalho, a luta" (BATAILLE, 2013, s/p). Georges Bataille inicia o longo poema Túmulo, que abre o livro $O$ arcangélico (L'archangélique,1944), assim: "Imensidade criminosa/ vaso rachado da imensidade/ ruína sem limites" (BATAILLE, 2015, p. 29), evocando a sensação de uma amplitude sem contornos, a morte este abismo a que um indivíduo tende, sua queda no infinito, a morte "loucura alada", "grito da noite definitiva", "desejo da noite" (Ibid, p. 29).

Que o livro de poemas de Georges Bataille seja sombrio, perturbador, de poética estranha e desesperada, é coerente com as inquietações que aparecem ao longo de toda a obra do autor, aqui dramatizadas no próprio ato da linguagem. $\mathrm{Na}$ apresentação à edição brasileira deste livro, chamada "Explosão em silêncio",

panfleto. Sua epígrafe traz outro cadáver, o próprio André Breton: "il ne faut pas que cet homme fasse de la poussière", "não é preciso que este homem vire pó".

${ }^{16}$ Lido no inglês: Georges Bataille - an intellectual biography. "What is surprising is not so much their discord as their obstinacy in not completely ignoring each other". 
Eliane Robert Moraes e Fernando Paixão sinalizam o paradoxo que encenam os poemas bataillianos: aí temos um “eu-lírico' que se apaga em cada verso, condenando seu próprio enunciado ao mais profundo silêncio" (MORAES, PAIXÃO; BATAILLE, 2015, p. 19), logo trata-se justamente de "ultrapassar o domínio verbal a partir do próprio verbo" (Ibid, p. 21), ideia que confirma-se na sensação de desamparo provocada pelo poema: desta experiência saímos com menos pontos de sustentação, menos certezas, dela sairemos menores, mais frágeis e instáveis. A quem poderá interessar este tipo de aniquilação? Talvez àqueles capazes de encontrar, nas fragilidades, suas maiores fortalezas. Ainda assim, esse poderá ser um projeto perigoso, tanto pessoal como coletivamente; isso se, em meio a tanto bombardeamento, não se puder erguer, de fato, outras fortalezas.

Está aí a noção de poesia como perda, fuga da linguagem do logos, de "criação por meio da perda" (BATAILLE, 2013, p. 23), que Bataille evocara no ensaio "A noção de despesa", apostando nas figuras de dispêndio. E também a noção da impossibilidade da morte - assim como a impossibilidade da palavra silêncio, a impossibilidade da poesia como linguagem e negação da linguagem que requer que ela seja vivida como dramatização. No ensaio "Hegel, a morte e o sacrifício" esta questão será abordada por Bataille: se é na morte em que o homem revela-se a si mesmo, seria então preciso morrer em vida, "olhando-se deixar de ser". Bataille vai afirmar: "O conhecimento da morte não pode deixar de se valer de um subterfúgio: o espetáculo" (BATAILLE, 2013, s/p), daí o sentido do sacrifício, em que a figura do sacrificante, identificando-se com a figura do animal ou do indivíduo morto, vê-se morrer. Assim, observa-se uma dinâmica espetaculosa em que a linguagem dramatiza a morte sacrificial como estratégia que possibilita um ver-se morrer através do outro.

Também Hilda Hilst encenou a morte e dela aproximou-se no livro de poemas Da Morte. Odes Mínimas, publicado pela primeira vez pela Massao Ohno/ Roswitha Kempf Editores ${ }^{17}$, em 1980, ano em que a autora completara 50 anos. Se a morte já ecoa como um dos grandes temas da obra poética e em prosa de Hilda Hilst, associada à solidão, à velhice, à perda, à desilusão amorosa, aqui o seu eu-poético vai confrontá-la de forma mais direta, mais íntima, na necessidade de trazê-la para perto. Hilda Hilst terá na morte uma interlocutora, a quem ela se dirige, evoca, chama, quer contato, de forma a tentar cercá-la e compreendê-la, vê-la chegar e se afastar, em uma interpelação entre duas fortes mulheres/ Na sua dura hora. Vejamos o poema que abre este livro:

\footnotetext{
${ }^{17}$ A edição das obras completas de Da morte. Odes mínimas contém 50 poemas divididos em três partes: a primeira $\mathrm{Da}$ morte. Odes mínimas, com quarenta poemas, Tempo-morte, com cinco, e À tua frente. Em vaidade, também com cinco. Além disso, na parte inicial são apresentadas suas aquarelas entre seis pequenos poemas. (Figura 4 e 5, p. 164, 165).
} 
Te batizar de novo.

Te nomear num trançado de teias

E ao invés de Morte

Te chamar Insana

Fulva

Feixe de flautas

Calha

Candeia

Palma, por que não?

Te recriar nuns arco-íris

Da alma, nuns possíveis

Construir teu nome

E cantar teus nomes perecíveis:

Palha

Corça

Nula

Praia

Por que não?

(HILST, 2013, p. 29)

Esta cena de abertura inaugura a relação do eu-poético com a morte, subvertendo os encaixes primeiros da linguagem para criar novos tipos de aproximação, proliferando os pontos de contato entre o eu e a morte, esta senhora onipresente, intensa participante da vida. Dramatiza-se aí a relação entre poeta e morte, de reconhecimento, aproximação: aí o movimento hilstiano de acercar-se do (des)conhecido a partir de uma investigação da linguagem, uma operação particular que revela ao mesmo tempo certa desconfiança das relações dadas e a necessidade de darem-se relações (outras), sendo preciso, portanto, rebatizar a prole. Isso porque não se pode dispor daquilo que não se conhece, como afirmava Hillé, A obscena senhora $D^{18}$ (1982), quando dizia: "Ehud, não posso dispor do que não conheço, não sei o que é corpo mãos boca sexo, não sei nada de você Ehud a não ser isso de estar sentado agora no degrau da escada, isso de me dizer palavras, nunca soube, você se deitava comigo, mesmo não sabendo" (HILST, 1993, p. 39).

No entanto, esse movimento parece tratar-se menos de uma tarefa nomeadora do que de uma operação de deslizamento entre os significantes, remetendo ao movimento paródico que Bataille evoca em $O$ ânus solar, de modo a indicar um devir ininterrupto que propõe a instabilidade dos nomes, outrora

\footnotetext{
${ }^{18}$ Este livro aparece com destaque na produção ficcional de Hilda Hilst: foi com ele que se inaugurou a edição das obras completas da autora pela editora Globo organizada por Alcir Pécora, que considerou que aí cruzavam-se os grandes temas da sua prosa de ficção. Para nós, $A$ senhora $D$ apresenta o lançar-se no fluxo de consciência - que, nesse caso, adquire forma dialógica, uma conversa entre Hillé e Ehud - de uma personagem que tende ao transbordamento de sua existência, no limiar de um processo ao mesmo tempo de dessubjetivação e de autoconstrução.
} 
talvez um dos últimos redutos de segurança e repouso. Se a linguagem é um dos alicerces do real, estrutura fundamental do mundo humano, a poesia por sua vez vai tratar de transgredir os limites desta organização, embaralhar os signos, de modo a evocar o movimento de continuidade e desfragmentação na tendência ao absoluto, tendência de morte. Mas a recusa de um nome próprio resulta ao mesmo tempo na proliferação de nomes, no exercício vertiginoso de resvalar e fixar, remetendo ao que Hilda Hilst realizou sobre os nomes dos órgãos sexuais e os nomes de Deus ${ }^{19}$, fazendo-os transbordar em diversos significantes, evidenciando o caráter redutor do nome próprio.

E se é preciso matar o animal a partir da "força monstruosa do entendimento" (BATAILLE, 2013, s/p) para fazer surgir o homem, a poesia em sentido contrário vai provocar a animalidade sufocada, incitar o ser separado e nomeado a um movimento de fusão e transbordamento, sua morte encenada. E se é preciso encarar essa fera de frente, assim como é preciso encarar de frente a morte, deste olho a olho não sairá mais que um vislumbre de noite, a sensação de abismo, o disparo acidental de uma arma, o momento sangrento de um ritual de sacrifício. Assim é que, assustadora e fascinante, a morte é, também "Amada/ Torpe/ Esquiva// Bem-vinda" (HILST, 2013, p. 32), como dirá o eu-poético das odes mínimas.

\section{REFERÊNCIAS}

BATAILLE, Georges. O erotismo. Traduzido por Antonio Carlos Viana. Porto Alegre: L\&PM, 1987.

O ânus solar (e outros textos). Traduzido por Aníbal Fernandes. Lisboa: Assírio e Alvim, 2007.

\footnotetext{
${ }^{19}$ Alcir Pécora tratou de relacionar todos os nomes dados aos órgãos sexuais que aparecem em Cartas de um sedutor. A quem interessar possa, transcrevo-os aqui. "Para o órgão sexual feminino: cona, biriba, rosa, xiruba, xerea, tabaca, mata, perseguida, xereca, pomba, cabeluda, prexeca, gaveta, garanhona, vulva, choca, xirica, pataca, caverna, gruta, fornalha, urinol, chambica, poça, xiriba, maldita, brecheca, camélia, bonina, nhaca, petúnia, babaca, "os meios", crica. Para o órgão masculino: bagre, mastruço, bastão, quiabo, rombudo, gaita, taco, ponteiro, sabiá, malho, verga, mangará, "um não sei quê", cipa, farfalho, chourição, picaço, cipó, estrovenga, toreba, besugo, porongo, envernizado, mondrongo, trabuco, bimbinha, fuso, mango, manjuba, pau-barbado, chonga, vara, ganso. Para a região fisiológica comum aos dois sexos: anel, rosquinha, buraco, rebembela, rodela, "o meu", pretinho, of, oiti, prega, rosquete, aro, regueira, cifra, mucumbuco, ó, mosqueiro, roxinho, pregueado, botão, borboleta, cibazol, jiló, cabo, bozó, besouro, chibiu, furo, porvarino, figo, babau" (PÉCORA, 2010, p. 21). E sobre a morte a profusão vocabular em Da morte. Odes mínimas elenca-se assim: Dorso mutante, Túrgida-mínima, cavalinha, cavalo, búfalo, Velhíssima-Pequenina, Menina-Morte, Caracol de sumos, Andorinha, Crina, Acróbata de guarda-sóis, amiga, Nada, Ventura, Rosto de Ninguém, Morte-Ventura, Prisma, Púrpura, Unguento, Duna, Riso, Sonido, Altura, minha-irmã, Tempo.
} 
A parte maldita - precedida de A noção de dispêndio. Traduzido por Fernando Scheibe. Belo Horizonte: Autêntica, 2013.

Hegel, a morte e o sacrifício. Traduzido por João Camilo Penna. Revista ALEA. Rio de Janeiro, v. 15/2, p. 389-413, jul-dez 2013. Disponível em: $<$ http://www.scielo.br/scielo.php?script=sci_arttext\&pid=S1517106X2013000200009>. Acesso em: 13 jun. de 2017. Autêntica, 2014.

O erotismo. Traduzido por Fernando Scheibe. Belo Horizonte: Poemas fora de série Georges Bataille. Organização e Tradução: Alexandre Rodrigues da Costa, Vera Casa Nova. Belo Horizonte: UFMG, 2015.

. O culpado - seguido de A aleluia. Traduzido por Fernando Scheibe. Belo Horizonte: Autêntica, 2017.

CHEVALIER, Jean; GHEERBRANT, Alain. Dicionário de Símbolos. Traduzido por Vera da Costa e Silva. Rio de Janeiro: José Olympio, 1998.

CIORAN, Emil. Silogismos da amargura. Trad. José Thomaz Brum. Rio de Janeiro: Rocco, 2011.

HILST, Hilda. A obscena senhora D. IN: Rútilo nada/ A obscena senhora D/ Qadós. Campinas: Pontes, 1993.

HILST, Hilda et al. Cadernos de literatura brasileira: Hilda Hilst. São Paulo, Instituto Moreira Salles, 1999.

. Da morte. Odes mínimas. São Paulo: Editora Globo, 2013.

- Pornochic - O caderno rosa de Lori Lamby/ Contos d'escárnio textos grotescos/ Cartas de um sedutor. São Paulo: Editora Globo, 2016.

KRISTEVA, Julia. Sol negro - depressão e melancolia. Rio de Janeiro: Rocco, 1989.

MORAES, Eliane Robert. O corpo impossível: a decomposição da figura humana: de Lautréamont a Bataille. São Paulo: Iluminuras, 2002.

MORAES, Eliane Robert; PAIXÃO, Fernando. Explosão em silêncio. In: Poemas fora de série Georges Bataille. Organização e Tradução: Alexandre Rodrigues da Costa, Vera Casa Nova. Belo Horizonte: UFMG, p. 18-23, 2015.

MORAES, Marcelo Jacques de. Georges Bataille e as formações do abjeto. Revista Outra travessia, Florianópolis, 2005, p. 107-120. Disponível em: https://periodicos.ufsc.br/index.php/Outra/article/viewFile/12586/11753 Acesso: 28 jul. 2017. 
PÉCORA, Alcir (org). Por que ler Hilda Hilst. São Paulo: Editora Globo, 2010.

PENNA, Camilo. Apresentação. Hegel, a morte e o sacrifício. Traduzido por João Camilo Penna. Revista ALEA. Rio de Janeiro, v. 15/2, p. 389-413, jul-dez 2013. Disponível em: $\quad<$ http://www.scielo.br/scielo.php?script=sci_arttext\& \&pid=S1517-106X2013000200009> Acesso em: 13 jun. 2017.

SCHEIBE, Fernando. Apresentação do tradutor. O erotismo. Traduzido por Fernando Scheibe. Belo Horizonte: Autêntica, p. 9-18, 2014.

SURYA, Michel. Georges Bataille: An intellectual biography. Trad. Krzysztof Fijalkowski and Michael Richardson. Londres: Versobooks, 2002.

Recebido em 29/9/2017

Aceito em 31/11/2017 